\title{
A SOLUÇÃO DE GERALDO ODON AO PARADOXO DO MENTIROSO
}

\author{
Ana Rieger Schmidt* \\ doi:10.11144/Javeriana.uph33-67.spdm
}

\section{RESUMO}

O presente artigo pretende inserir o teólogo franciscano Geraldo Odon (ca.1290-1349) no debate historiográfico medieval acerca das diferentes soluções oferecidas ao célebre paradoxo do mentiroso. Na primeira parte a autora apresenta rapidamente e de forma esquemática os principais tipos de solução ao sofisma para em seguida analisar o texto de Odon, respondendo à questão da sua originalidade.

Palavras chave: Geraldo Odon; paradoxo; mentiroso; sophismata; insolubilia

* Universidade Federal do Rio Grande do Sul, Porto Alegre, Brasil.

Correo electrónico: ana.rieger@gmail.com

Para citar este artículo: Rieger SCHMidT, A. (2016). A solução de Geraldo Odon ao paradoxo do mentiroso. Universitas Philosophica, 33(67), pp. 303-319. ISSN 0120-5323, ISSN en línea: 23462426, doi:10.11144/Javeriana.uph33-67.spdm 


\title{
THE GERALDUS ODONIS' SOLUTION TO THE LIAR PARADOX
}

\author{
Ana Rieger Schmidt
}

\begin{abstract}
The article aims to introduce the Franciscan theologian Geraldus Odonis (ca.1290-1349) into the medieval historiographical debate about the different solutions offered to the famous liar paradox. In the first part the author presents briefly and in a schematic way the main kinds of solution to the sophism to then analyze Odon's text, answering the question of its originality.
\end{abstract}

Key words: Geraldus Odonis; paradox; liar; sofismata; insolubilia 


\section{Soluções ao paradoxo do mentiroso na Idade Média}

PROCURAREI, EM UM PRIMEIRO MOMENTO, traçar brevemente segundo uma ordem cronológica as principais soluções oferecidas ao paradoxo do mentiroso para poder, na segunda parte desta exposição, expor a solução de Geraldo Odon (ca.1290-1349) ${ }^{1}$. Meu objetivo será então o de apreciar a seguinte questão-guia: a solução de Odon ao paradoxo do mentiroso é uma variação das soluções já conhecidas ou constitui uma resposta original?

"Ego dico falsum" - o paradoxo do mentiroso é certamente a mais conhecida das antinomias da linguagem. Presença assídua na literatura medieval, encontramos problematizações a seu respeito já em textos lógicos do final do século XII até o final do século XVI, seja nos tratados dedicados aos insolubilia, sophismata ou ainda na tradição de comentários às Refutações Sofísticas de Aristóteles, obra à qual remonta a origem da discussão medieval sobre paradoxos.

No texto de Aristóteles, o paradoxo do mentiroso aparece como um elemento do conjunto de falácias que confundem a verdade simpliciter com a verdade secumdum quid. Nesse contexto, o Filósofo invoca o exemplo de um homem que jura romper seu juramento, e de fato o rompe ${ }^{2}$. Simpliciter, esse homem não é um cumpridor de seus juramentos, embora cumpra esse juramento em particular. Em seguida, Aristóteles aplica o mesmo raciocínio ao mentiroso:

$\mathrm{O}$ argumento se assemelha ao <problema de saber> se o mesmo homem pode dizer ao mesmo tempo o que é verdadeiro e o que é falso; mas o problema parece ser de difícil investigação, pois não é fácil perceber em qual dos lados se pode atribuir < a qualificação > simpliciter — se ao verdadeiro ou ao falso. Nada o impede, porém, de ser mentiroso simpliciter, embora

1 Franciscano, Odon que lê as Sentenças em Paris no início dos anos 1320 e é autor de uma série de tratados lógicos, dentre os quais o De principiis scientiarum, ou sobre os primeiros princípios das ciências.

2 Aristóteles, Refutações Sofísticas, 25, 180a35-b (Aristoteles Latinus, IV. 1-3, 1975, p.49): Ergo contingit eundem simul bene iurare et periurare? Ergo possibile est eundem simul eidem suadere et dissuadere, aut non et esse quid et esse idem? Quod autem non est, non si est quid, et est simpliciter; neque si bene iurat, hoc aut secundum hoc, necesse est et bene iurare; nam qui iurat periuraturum bene iurat periurans hoc solum, bene autem iurat non; neque qui dissuadet suadet, sed quid suadet. 
verdadeiro sob outro aspecto ou outra coisa particular, isto é, verdadeiro quanto a determinadas coisas, mas não verdadeiro < simpliciter $>{ }^{3}$

Se a recepção das Refutaçôes Sofísticas no mundo latino passou a chamar a atenção dos medievais para os paradoxos, mas sua resolução não se limitou a autoridade de Aristóteles. De fato, a partir dos anos 1320 a lógica medieval conhece um rico debate no que toca à solução de paradoxos e, em especial, ao paradoxo do mentiroso.

Seguindo os trabalhos pioneiros de Vincent Spade $(1983,1987)^{4}$, podemos distinguir, além da solução de inspiração Aristotélica, quatro principais tipos de soluções anteriores a 1320, momento em que Tomás Bradwardine escreve seu tratado sobre os Insolúveis, considerado como um novo momento na resolução de paradoxos.

(I) Uma primeira opinião, reportada por Walter Burley e por Bradwardine em seus tratados sobre os insolúveis ${ }^{5}$, referida como transcasus, pretende que, ao pronunciarmos a proposição "eu digo o falso", ou "eu estou mentindo", o verbo (mesmo que se encontre no tempo presente) se refere a uma proposição proferida anteriormente, operando assim um transcasus (uma espécie de salto gramatical) barrando a auto-referência, ou seja, a proposição não se refere a ela mesma, desfazendo o paradoxo.

3 Aristóteles, Refutaçôes Sofisticas, 25, $180 \mathrm{~b}-7$ (Aristoteles Latinus, IV. 1-3, 1975, p.49): [...] similis autem ratio et de eo quod est mentiri eundem simul et verum esse; sed quia non est facile inspicere, utro modo quis assignet simpliciter verum esse vel mentiri, difficile videtur. Probibet autem eundem nichil simpliciter quidem esse mendacem, quo autem verum vel aliquo, et esse verum aliquem, verum autem non.

4 Ver: sobre o paradoxo do mentiroso no século XIV, Read, 2002 pp. 189-218; para os séculos anteriores, Spade, 1987, 1983.

5 Bradwardine se refere a esta opinião como "restringentium tempus", e não exatamente como “transcasus". Ver: Tomás Bradwardine, Insolubilia, \$5.04, p. 294: “Quarta oppinio est restringentium tempus, ut premissum est. Qui sic nominan tur pro tanto quia dicebant quod Sorte dicente: Sortes dicit falsum, hoc verbum dicit licet sit presentis temporis, tamen debet intelligi pro tem-pore sive instanti immediate precedente tempus prolationis”; \$2.07, p. 270: “Et est transcasus quando aliqua propositio mutatur a veritate in falsitatem vel e converso. (...) Unde dicunt quod me dicente me dicere falsum, si postea quaeratur: aut dico verum aut falsum, dicunt quod falsum, quia aliud est tempus in quo dico aliquid et pro quo dico aliquid. Ideo si dico me dicere falsum, dico hoc pro tempore precedente; et quia in tempore precedente nibil dixi, ideo in dicendo me dicere falsum, dico falsum, quia dico aliter quam est in re". 
(II) O segundo grupo, rotulado pela literatura secundária como cassantes, propunha que aqueles que proferem um paradoxo, um sofisma, não significam nada. Um paradoxo não é propriamente uma proposição, mas uma frase desprovida de sentido. Essa posição não gozou de grande popularidade: ela é sustentada por tratados anônimos do início do século XIII (os mais antigos aos quais temos acesso $^{6}$ ), mas parece ter sido abandonada depois de 1225 e apenas retomada na literatura posterior para ser criticada. A crítica mais conhecida é a de Bradwardine, a qual foi basicamente repetida pelos seus sucessores. Segundo o lógico inglês, o mentiroso obviamente diz algo, pois pronuncia sílabas e palavras com sentido, e forma com elas uma sentença da qual entendemos algo. Essa crítica certamente a toma a posição dos cassantes como demasiado ingênua, taxada por Bradwardine como contrária a sensação e ao intelecto ${ }^{7}$.

(III) O terceiro grupo, conhecido como restringentes, recusa a auto-referência, ou seja, limita a referência do sujeito da proposição, o qual não pode recair sobre ela mesma. Segundo eles, "uma parte são pode supor pelo todo do qual ela é uma parte" —onde o "supor" deve ser entendido no sentido técnico "suppositio", uma propriedade de termos categoremáticos no contexto de uma proposição. Podemos distinguir duas versões dessa posição: uma mais forte- que proíbe toda e qualquer auto-referência; e uma mais moderada — que proíbe a auto-referência apenas nos casos paradoxais. Essa posição é frequentemente reportada e criticada na literatura, como em Bradwadine e, veremos mais adiante, no próprio Geraldo Odon. Ao contrário dos cassantes, que deixaram de ser defendidos, os restringentes ainda encontram defensores no século XIV ${ }^{8}$.

(IV) Uma quarta resposta pode ser listada ao lado das precedentes: Duns Scotus procura dar conta do paradoxo através da distinção entre ato exercido (actus exercitus) e ato significado (actus significatus). No caso da proposição "eu digo o falso", o ato significado corresponde ao conteúdo da minha fala, a saber:

6 Ver: Rijk, 1966; Spade, 1987, p. 29.

7 Tomás Bradwardine, Insolubilia, \$5.05, p. 295: “Sed isti contradicunt sensui et intellectui”; Burley, Insolubilia, \$2.03, p. 269: "Praeterea ipsi negant sensum: quia ipsi possunt audire Sortem dicere se dicere falsum, ergo Sortem dicere falsum potest dici a Sorte”.

8 Henrique da Inglaterra e Ricardo Brinkley sustentaram versões fortes da restrictio. Ver: Spade, 1987, p. 42, n. 83 . 
dizendo o falso; o ato exercido corresponde àquilo que eu estou fazendo quando digo que digo o falso, a saber, dizendo a verdade. Assim, para Scotus há falsidade no ato significado e verdade no ato exercido ${ }^{9}$. Desse modo, a verdade e a falsidade não são atribuídos ao mesmo ato, ao mesmo discurso. Essa solução é mencionada (e rejeitada) por Bradwardine em termos parecidos com os de Scotus, mas possivelmente visando outros proponentes ${ }^{10}$.

(V) Finalmente, chegamos às soluções de Bradwardine e de Buridan, que, para efeitos práticos trataremos conjuntamente. Para os dois lógicos, o paradoxo do mentiroso (e demais insolúveis desse tipo) são simplesmente falsos.

Convém notar que Tomás Bradwardine (c. 1300-1349) escreve seu tratado dos Insolúveis em Oxford entre 1321 e 1324 - portanto, no mesmo momento em que Geraldo Odon escreve seu tratado lógico em Paris. Como já dito, o texto de Bradwardine gozou de uma considerável popularidade. Com efeito, encontramos retomadas da sua posição em diversos autores, como o já mencionado Buridan, mas também Pedro de Saxe, Pedro d'Ailly e Paulo de Veneza. Considera-se também que Gregório de Rimini e Marsílio de Inghen tenham apresentado variações da mesma posição ${ }^{11}$.

O núcleo da solução de Bradwardine consiste na regra geral segundo a qual "Se uma proposição significa que ela mesma não é verdadeira ou que é falsa, então ela significa que ela não é verdadeira e é falsa" ${ }^{12}$. Essa regra será aplicada aos insolúveis, e ao paradoxo do mentiroso em especial. Ela é baseada sobre a seguinte tese: uma proposição significa tudo o que se segue daquilo que ela significa [primeiramente]. Isso quer dizer que se uma proposição implica uma falsidade, então ela a significa, ainda que indiretamente. Desse modo, uma proposição que implica

9 João Duns Scotus, Quaestiones super libros Elenchorum, q. 53, ad 1, p. 270: “(...) sed in proposito falsitas est in actu significato, et veritas in actu exercito".

10 Tomás Bradwardine, Insolubilia, \$5.08, p. 296: “Octava oppinio est distinguentium. Qui ob hoc tale nomen acceperunt quia Sorte dicente Sortem dicere falsum distinguebant de dicere penes equivocationem. Potest enim significare dicere exercitum vel conceptum. Et vocant 'dicere exercitum' dicere quod est in exercitio, et est illius quod est in dici et non est dictum complete; 'dicere vero conceptum', dicunt, cum homo prius dixerit aliquid vel aliquale et instanti post dicat se dicere illud vel tale".

11 Ver: Spade, 1975; 1981 p. 123 n. 32; Biard, 1993, p. 249, nota 2.

12 Tomás Bradwardine, Insolubilia, $\$ 6.05$, p. 298: "si aliqua propositio signicat se non esse veram vel se esse falsam ipsam, signicat se non esse veram et est falsa”. 
algo falso não pode ser verdadeira. No caso dos paradoxos, que implicam sua própria falsidade, conclui-se que não podem ser verdadeiros.

Apliquemos esse raciocínio ao paradoxo do mentiroso: Sócrates afirma dizer uma falsidade - e essa é a única frase que ele profere. Então, se a sua afirmação é verdadeira, ela seria também falsa, pois é isso o que ele está dizendo: uma falsidade. No entanto, porque ela é falsa, ele seria imediatamente verdadeira, pois foi isso que Sócrates disse que faria; Sócrates descreve o que de fato está fazendo: mentindo. A solução de Bradwardine pretende barrar essa segunda consequência do paradoxo, a saber, a passagem do falso para o verdadeiro ${ }^{13}$. Assim, ainda que seja verdade que Sócrates esteja dizendo o falso, a proposição "Sócrates mente", ou "Sócrates diz o falso" é simplesmente falsa.

Vinte anos depois, João Buridan descreve sua solução ao paradoxo do mentiroso em termos semelhantes aos de Bradwardine. Há certa discordância entre as interpretações da solução de Buridan e suas implicações para a sua teoria da verdade como um todo ${ }^{14}$. Todavia, nosso objetivo não é tomar posição nesse debate, tampouco descrever o pensamento lógico de Buridan em profundidade. Para nossos efeitos, vamos nos contentar com a apresentação da sua solução tal como presente em seu Sophismata.

Vejamos primeiramente o que diz Buridan a respeito do sofisma "toda proposição é falsa”, que pode ser considerado uma variação do mentiroso:

Assim, toda proposição que afirma ser falsa, seja direta ou implicitamente, é falsa, pois ainda que <a realidade $>$ seja assim como ela signifique ser, na medida em que significa ser ela mesma falsa, [a realidade] não é assim como ela significa ser, na medida em que significa que ela é verdadeira. Assim, ela é falsa e não verdadeira, pois para a verdade da proposição, é requerido não somente que <a realidade > seja assim como ela significa, mas que ela seja da maneira como ela significa ser. ${ }^{15}$

13 Ver: Read, 2009, pp. 363-375.

14 Ver: Perini-Santos, 2011, pp. 184-213.

15 Buridan, Sophismata, VIII, soph., 7, p. 154: "Ideo omnis propositio asserens se esse falsam, sive directe sive consecutive, est falsa, quia licet qualiter significet esse ita sit quantum ad hoc quod significat se esse falsam, tamen non qualiter significat esse ita est quantum ad hoc quod significat se esse veram. Ideo est falsa et non vera, quia ad veritatem requiritur non solum quod qualiter significat ita sit, sed quod qualitercumque significat ita sit". 
Mais adiante, Buridan parece mostrar que a falsidade do paradoxo do mentiroso se deve à falsidade daquilo que ele implica virtualmente:

Qualquer proposição implica uma outra proposição, pela qual o predicado "verdadeiro" seria afirmado de um sujeito que supõe por ela. Eu digo "implica virtualmente" (implicat virtualiter), assim como o antecedente que implica o que se segue dele. ${ }^{16}$

Isso quer dizer que as condições de verdade de uma proposição devem compreender os referentes (supposita) do sujeito e do predicado e também a verdade do seu consequente, ou seja, essa segunda proposição implicada pela proposição original. Estes resultados são aplicados ao paradoxo do mentiroso, o qual é considerado absolutamente falso, na medida em que a proposição implica algo fal$\mathrm{so}^{17}$. Portanto, as coisas não são exatamente tal como o paradoxo as descreve. Visto que se algo falso se segue desta proposição "Sócrates diz o falso", ou "eu digo o falso", então, ainda que ela se pretenda verdadeira e falsa ao mesmo tempo, ela é simplesmente falsa, em função da impossibilidade que ela implica.

Assim, encontramos diversos tipos de solução ao paradoxo do mentiroso: a primeira de inspiração diretamente aristotélica, segundo a qual esse tipo de paradoxo é considerado falso simpliciter, ainda que seja concedido que ele seja verdadeiro secundum quid; a solução pela qual esse tipo de proposição é desprovida de sentido, e portanto a rigor não é nem verdadeira nem falsa; as soluções que visam barrar a possibilidade da auto-referência (em geral ou apenas para as proposições problemáticas); a solução que pretende distinguir dois atos (exercido e significado), visando evitar que valores de verdade contraditórios sejam atribuídos a mesma proposição sob o mesmo aspecto; por último, as soluções que determinam que o paradoxo é falso em função do que se encontra virtualmente implicado nele, a saber, a sua própria falsidade, de modo que ele não é verdadeiro e falso ao mesmo tempo.

16 Buridan, Sophismata, VIII, soph., 7, p. 154: “(...) quaelibet propositio implicat virtualiter aliam propositionem de cujus subjecto pro ea supponente affirmatur hoc praedicatum 'verum'; dico 'implicat virutaliter'sicut antecedens implicat illud quod ad sum sequitur".

17 Buridan, Sophismata, cap. VIII, Sofisma 11. 


\section{A solução de Geraldo Odon}

Dito ISSO, ESTAMOS EM POSSE DOS ELEMENTOS NECESSÁRIOS para apreciar a solução de Geraldo Odon. Deve-se notar, em primeiro lugar, uma particularidade com relação ao texto de Odon: a discussão aparece em um contexto diferente daquele no qual os paradoxos normalmente eram discutidos, a saber, os tratados dedicados aos insolubilia ou os comentários às Refutaçôes Sofísticas de Aristóteles. Odon introduz a discussão sobre o mentiroso no tratado Dos primeiros princípios: um texto de mais de 200 páginas dedicado inteiramente à natureza e às propriedades dos princípios de não-contradição e do terceiro excluído. O capítulo IV desse tratado procura defender a verdade irrestrita e incondicional dos princípios face aos seus adversários. Segundo Odon, existem duas maneiras de fazer isso: a primeira é positivamente, fornecendo prova da sua validade absoluta e da incoerência daqueles que o negam (trata-se da célebre estratégia elênctica de argumentação). Outra é negativamente, refutando os sofismas formulados contra os primeiros princípios, os quais parecem implicar a possibilidade da contradição. $\mathrm{O}$ conjunto dos sofismas reunidos por Odon é vasto e conta com argumentos bem conhecidos, como por exemplo os argumentos de Heráclito a partir da natureza do movimento ${ }^{18}$, e o pai dos paradoxos semânticos: o paradoxo do mentiroso.

A proposição ego dico falsum é apresentada como um argumento contra o princípio de não-contradição, na medida em que ela implicaria a sua verdade e falsidade simultâneas. Ao mesmo tempo em que o sujeito diz uma falsidade, ele está dizendo algo de verdadeiro: a saber, que ele mente! Cada membro da contradição «pé $\mathrm{V}$ - $p$ é $\mathrm{F}$ » implica o outro (utraque contradictoria infert aliam): se p é verdadeiro, ele é falso; se falso, verdadeiro ${ }^{19}$. Mostrar que o paradoxo não invalida o princípio de não-contradição significa encontrar uma solução para o mesmo.

18 Ver: Geraldo Odon, De principiis scientiarum, IV, \$14, p. 384; Aristóteles, Física, III, 5, 205²-3; VI, 5, 236a35-b9.

19 Geraldo Odon, De principiis scientiarum, IV, \$10, p. 382: "Hec proposition 'ego dico falsum' vocetur B. Tunc sumo hanc contradictionem 'B est falsa' - 'B non est falsa'. Quare Une sequitur ad alteram, quoniam, si B est falsa, sequitur quod non est falsa, quia enuntiat sicut est et non aliter quam est. Si vero $B$ non est falsa, sequitur quod est falsa, quoniam aliter est quam ipsa enuntiat. Et sic utraque contradictoria infert aliam". 
Odon começa criticando três soluções para o paradoxo. A primeira é rapidamente apresentada (e tão logo rejeitada), de modo que não pudemos identificar seus possíveis defensores. Segundo ela, "na proposição 'eu digo o falso", existem virtualmente duas proposições. Uma é esta: 'eu digo [algo]" (a qual é verdadeira); a outra é "isto é falso" (a qual é falsa)"20. Assim, não se trata da mesma proposição que é verdadeira e falsa ao mesmo tempo, mas de duas proposições que, resultantes da análise do paradoxo, dividem os dois valores de verdade entre si: uma é verdadeira e a outra é falsa. Para refutar essa solução, Odon oferece uma versão do mesmo paradoxo que não pode ser analisada, ou desmembrada em dois: "esta minha proposição é falsa". Sem comportar dois verbos, não se pode depreender duas proposições distintas, de modo que a dificuldade retorna.

Odon refuta em seguida duas posições restringentes: primeiramente em sua versão radical e em seguida em sua versão moderada. A versão radical defende que o que caracteriza esse paradoxo é a auto-referência: "a saber, quando um termo supõe pela totalidade da proposição da qual ele é parte"21. O mesmo vale para outra versão do sofisma: "toda proposição é falsa" (omnis propositio est falsa). Esse tipo de proposição, segundo a explicação reproduzida por Odon, não se sustenta, pois nenhuma proposição pode referir a ela mesma através de um de seus termos. Para mostrar que tal solução não é adequada, Odon se contenta em fornecer um contra-exemplo: a proposição "tota proposição é uma oração" (omnis propositio est oratio) é verdadeira e comporta auto-referência. O problema dessa explicação é, portanto, que ela exclui não apenas os casos viciosos de auto-referência, mas aqueles casos inócuos que não teríamos razões para banir.

20 Geraldo Odon, De principiis scientiarum, IV, $\$ 42:$ "Ad aliud dicunt aliqui, cum dicitur 'ego dico falsum', hic sunt due propositiones virtualiter; uma est hec: 'ego dico' (et hec est vera), alia est hec: 'istum est falsum' (et hec est falsa). Sed hoc nichil est, quia, dicendo sic 'bec propositio mea est falsa', non potest referri ad plures propositiones, et tunc est hic <eadem > difficultas que fuit in prima".

21 Geraldo Odon, De principiis scientiarum, IV, \$43: "Propter quod dicunt alii quod hic est unum impossibile, scilicet quod aliquis terminus supponat pro tota oratione cuius est pars et terminus; et si fiat talis oratio, non est sustienda. Sed nec istud valet quicquam. Probatio quoniam : Si dicatur : 'omnis propositio est falsa', hic terminus 'propositio' supponit pro ista cuius est pars et terminus (...). Contra quia : Hec est sustinenda ut verissima 'omnis propositio est oratio". 
Já a versão restringente moderada aceita a auto-referência em alguns casos específicos, embora de modo geral ela deva ser evitada ${ }^{22}$. Odon responde curiosamente a essa solução:

Em sentido contrário: Se disser a alguém e depois não proferir < $\operatorname{mais}$ nada $>$ :

"minha última proposição é falsa"; essa será a sua última proposição, e apenas

permanece aqui toda a dificuldade que havia no início. ${ }^{23}$

Odon parece entender que a proposição "minha última proposição é falsa" escapa à auto-referência, ao mesmo tempo que continua sendo paradoxal. De fato, o contra-exemplo apresentado depende de que nada mais seja proferido além da própria proposição para que a dificuldade ocorra, e nesse sentido ele difere das outros casos de auto-referência citados, a saber, "eu digo o falso", "esta proposição é falsa”, ou ainda "toda proposição é falsa”. Porém, não conseguimos ver como o suposto contra-exemplo de Odon escaparia a um caso especial de auto-referência, concedido que não nada seja proferido anteriormente ao paradoxo.

Sem nos determos mais nas críticas às soluções ao paradoxo elencadas por Odon, passaremos à parte positiva de sua exposição, na qual ele apresenta sua própria solução. Ela é constituída de três momentos: no primeiro, a estrutura geral da proposição e de seu mecanismo de verificação é apresentado. Com base nessa explicação, o paradoxo é confrontado à proposição "saudável", de modo que suas falhas ( 4 exatamente) são evidenciadas. Por último, Odon pode identificar a natureza da principal falácia envolvida no paradoxo e determinar o seu valor de verdade (Odon identifica 3 falácias, mas tratarei somente da primeira, que julgo ser o núcleo da solução).

Odon confronta o paradoxo a um esquema da significação proposicional. Ele nos explica que as proposições podem ser analisadas em quatro elementos: A proposição que enuncia (propositio enuntians), o objeto que ela enuncia (obiectum de quo enuntiat), a verdade ou falsidade na proposição (veritas vel falsitas in

22 Geraldo Odon, De principiis scientiarum, IV, \$44: "Propter quod addunt isti et illi quod terminus potest supponere in generali pro oratione cuius est pars et terminus in generali, ut in predictis orationibus, non autem in speciali".

23 Geraldo Odon, De principiis scientiarum, IV, \$44: “Sed contra: Si dicat aliquis et postea non loquatur: 'ultima mea propositio est falsa', hec erit propositio sua et ultima, et modo remanet hic tota difficultas que fuit a principio, quare omnia sunt inaniter dicta". 
propositione) e a causa da sua verdade ou falsidade presente no objeto da proposição (causa veritatis vel falsitatis in obiecto propositionis).

Esses quatro elementos são colocados em relação: assim como, do lado da proposição, encontramos o sujeito e o predicado unidos ou divididos pela cópula afirmativa ou negativa; assim também encontramos, do lado do objeto, os referentes do sujeito e do predicado compostos ou divididos, em correspondência com a cópula da proposição que os significa. Os valores de verdade aparecem como efeitos causados pela adequação da composição ou divisão no objeto com cópula $a^{24}$.

Propomos representar esse esquema da seguinte forma:

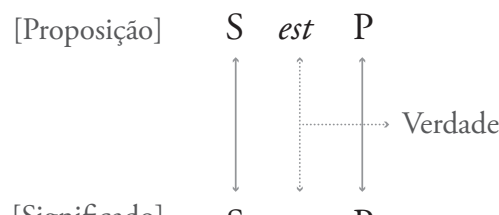

[Significado] $\mathrm{S}$ est $\mathrm{P}$

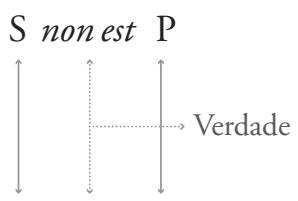

$S$ non est $\mathrm{P}$

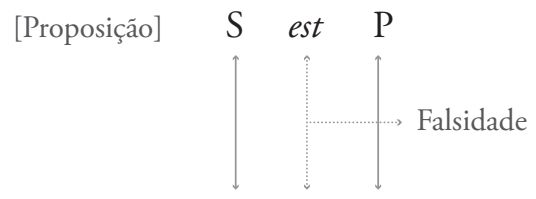

[Significado]

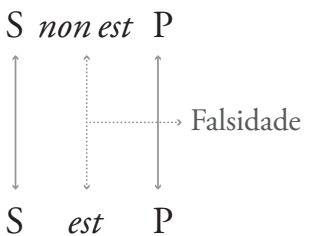

Cabe notar que tal esquema deve ser compreendido dentro do realismo proposicional de Odon. Sabe-se que na idade média, em especial no século XIV, a questão "ao quê corresponde a proposição?" recebeu ao menos dois tipos de resposta: enquanto os nominalistas reduzem o significado da proposição aos significados dos seus termos, os realistas admitem haver algo que corresponda ao

24 Geraldo Odon, De principiis scientiarum, IV, \$45, p. 396: “Propter quod primo ostendam malitiam huius propositionis; secundo respondebo. Propter primum sciendum primo quod circa enuntiationes concunrrunt quatuor, scilicet propositio enuntians, et obiectum de quo enuntiant, et veritas vel falsitas in propositione, et causa veritatis vel falsitatis in obiecto propositionis. Secundo quod, sicut in propositione est subiectum et predicatum et eorum copula affirmativa vel negativa, ita ex parte obiecti est obiectum subiecti et obiectum predicati et corum compositio vel divisio correspondens affirmationi vel negationi. Tertio quod compositio in obiecto est causa veritatis affirmative et causa veritatis negative; divisio vero est causa veritatis negative et causa falsitatis affirmative". 
significado da totalidade da proposição, o qual é irredutível aos significados dos termos que a compõem. De uma maneira geral, podemos caracterizar uma teoria realista da proposição pela aceitação dos três pontos seguintes: (i) A proposição mental possui um significado próprio; (ii) $\mathrm{O}$ significado próprio não possui o mesmo modo de ser da proposição mental. O que implica: (iii) A admissão de entidades extramentais às quais tais significados correspondem.

Não é nosso objetivo desenvolver essa argumentação aqui ${ }^{25}$, mesmo porque ela não influencia a solução ao paradoxo. Apenas chamamos a atenção para o fato de que devemos considerar Odon como um realista, em virtude da objetividade própria que ele confere ao objeto da significação, que ele chama de coisa lógica (res logicaliter sumpta), a qual corresponde à cópula proposicional - que Odon chamará de ens tertio adiacens, uma entidade de importância capital no tratado do lógico franciscano. Isso significa que, no esquema acima, a verificação da proposição mental, escrita ou proferida se dá pelo seu significado total e final, que é causa primeira da verdade proposicional.

A partir desse esquema da verificação proposicional, Odon pode subeter o paradoxo a crítica, e identificar os seus pontos problemáticos.

\section{As quatro "malícias" do paradoxo}

A resposta de Odon parece Ser uma combinação de pelo menos duas soluções. Visto que o problema não é a auto-referência operada no paradoxo, a falha deve se encontrar em outro aspecto da proposição. Odon mostra como o paradoxo comete uma série de problemas estruturais, as quais ele chama de "malícias". Primeiramente, há o deslocamento do valor de verdade para o interior da proposição (ou seja, como teu predicado), então, uma propriedade da proposição (passio propositionis) é confundida com a sua parte:

(...) a proposição 'eu digo o falso', ou "minha última proposição é falsa”, possui quatro malícias. Pela primeira, parte da proposição é tomada como uma propriedade da proposição; ou seja, a falsidade, tal como é tomada aqui, é a

25 Para uma discussão sobre o realismo proposicional de Odon, consultar meu artigo "O ens tertio adiacens de Gerardo Odon e o realismo proposicional", a ser publicado na revista de filosofia Kriterion, da Universidade Federal de Minas Gerais (Brasil). 
propriedade da proposição, e aqui é tomada como parte da mesma proposição. Porém, isso não induz a uma impossibilidade, mas a uma dificuldade. ${ }^{26}$

Essa falha estrutural acarreta duas outras: a confusão da causa com o efeito, e do anterior com o posterior. Ora, uma proposição é dita verdadeira ou falsa do momento em que ela é confrontada com o seu verificador, o qual é causa do seu valor de verdade ${ }^{27}$. Ao tomar o valor de verdade como predicado, o paradoxo desrespeita essa ordem causal da verificação.

Por outro lado, Odon aponta para a incompatibilidade entre a forma afirmativa da proposição e o predicado "falso": enquanto a primeira significa a união do sujeito com o predicado, o segundo significa a separação dos mesmos. Esta instabilidade representa, segundo Odon, a maior malícia do paradoxo:

Em quarto lugar — onde se esconde a lebre $-<$ o sofisma $>$ diz unir e não unir o predicado com o sujeito ao mesmo tempo. O que é patente pois toda proposição afirmativa informa uma união; ora, a proposição em questão é afirmativa, porque diz unir o predicado com o sujeito; mas este predicado "falso" diz não unir o predicado com o sujeito na proposição afirmativa à qual ele é atribuído. Isso se dá desta maneira porque essa proposição é afirmativa e seu sujeito supóe pela sua totalidade, e seu predicado denota pela sua totalidade. Pois a mesma diz, a partir da forma enunciativa, unir os extremos, e a partir da razão do predicado diz não uni-los. E nisso aparece de que modo <essa proposição> é sumamente maliciosa. ${ }^{28}$

26 Geraldo Odon, De principiis scientiarum, IV, \$46: “(...) hec propositio 'ego dico falsum', vel hec 'ultima propositio mea est falsa, habet has quatuor malitias. Primo quia parte propositionis facit passionem propositionis; falsitas enim, ut hic sumitur, est passio propositionis, et cum hoc sumitur hic ut pars eiusdem propositionis. Hoc autem non inducit impossibilitatem, sed difficultatem".

27 Geraldo Odon, De principiis scientiarum, IV, \$46: "Secundo autem facit effectum de causa et causam de effectu; falsitas enim est effectus terminorum propositionis et copule eorum secundum quod sumuntur pro obiecto; ipsa tamen sumitur hic ut causa eiusdem. Tertio facit idem prius et posterius sicut causam et causatum".

28 Geraldo Odon, De principiis scientiarum, IV, \$46: “Quarto vero, ubi latet lepus, notat predicatum uniri et non uniri subiecto simul et semel. Quod patet quia quelibet affirmativa notat huiusmodi unionem ; hec autem propositio est afirmativa; quare notat predicatum uniri cum subiecto; sed istud predicatum 'falsum' notat non uniri predicatum cum subiecto in propositione afirmativa, cui attribuitur. Sic autem est hic quoniam hec propositio est afirmativa et eius subiectum supponit pro tota ea, et eius predicatum denotat eam totam. Quare ipsa notat ex forma enuntiandi extrema uniri, et ex ratione predicati notat ea non uniri. Et in hiis apparet quomodo est summe matitiosa". 
Odon identifica, assim, a incompatibilidade entre a composição significada pela forma afirmativa do paradoxo e a divisão significada pelo seu predicado. Dado que tanto o sujeito como o predicado denotam a própria proposição, então têm-se o seguinte par contraditório: "S é P" e $S$ não é P". Observe-se de que o problema não é a auto-referência, mas o fato de que a mesma proposição coloca uma união e uma divisão com relação a si mesma, com relação à mesma cópula.

A identificação dessa particularidade leva Odon a analisar as condições de verdade do sofisma, tornando possível a determinação do seu valor de verdade e, com isso, resolver a dificuldade. Isso pode ser feito graças à identificação de uma falácia, denominada "muitas interrogações como uma" ${ }^{29}$, ou se podemos reformular essa nomenclatura para aproxima-la do nosso problema, "muitas proposições travestidas de uma”. Em outras palavras, o paradoxo comportaria duas proposições de maneira implícita, de modo que o seu valor de verdade deve ser determinado pela conjunção de duas proposições. Como o conjunto inconsistente "eu digo o verdadeiro - eu digo o falso" não pode ser verificado, a proposição não pode ser ela mesma verificada, e é em consequência falsa.

Agora respondo dizendo que <a proposição "eu digo o falso"> é falsa. E quando é inferido 'portanto não é falsa', nego a consequência. E quando é provado porque « então enuncia segundo <a realidade> é », não se segue, mas erra por três falácias. E mostro a primeira: "muitas interrogações como uma”. Aqui existem implicitamente duas <proposições> contraditórias. Eis a razão pela qual interrogar sobre a verdade ou a falsidade dessa proposição é interrogar sobre dois contraditórios. Assim, digo que uma proposição implicando essas duas informaçóes contraditórias é falsa, pois para sua verdade seria requerido que cada uma fosse verdadeira, ou que cada uma fosse nãofalsa. Porém, quando digo que ela é falsa, quero dizer que ambas não são verdadeiras, ou que ambas são não-falsas. ${ }^{30}$

29 Ver: Aristóteles, Refutaçōes Sofisticas, 6, 169ª 6-21.

30 Geraldo Odon, De principiis scientiarum, IV, \$47: "Nunc autem respondeo dicens quod est falsa. Et cum infertur 'ergo non est falsa', nego consequentiam. Et cum probatur quia: "tunc enuntiat sicut est", non sequitur, ymo peccat per tres fallacias. Et ostendo primo « plures interrogationes ut unam ». Hic enim sunt due contradictorie implicite. Quare interrogare de veritate vel falsitate huius propositionis est interrogare de duobus contradictoriis. Quare dico quod propositio implicans has duas notas contradictorias est falsa, quoniam ad eius veritatem requireretur quod utraque esset vera. Cum autem ego dico quod est falsa, volo dicere quod non utraque est vera, vel non utraque est non-falsa". 
Assim, o paradoxo do mentiroso não é verdadeiro e falso ao mesmo tempo, mas simplesmente falso. $\mathrm{O}$ princípio de não-contradição segue universalmente válido. Vemos, portanto, que o paradoxo é extremamente problemático e não respeita a estrutura proposicional, ou mais precisamente, o mecanismo de verificação proposicional tal como Odon o concebe. Vemos também que as "malícias" listadas por Odon não culminam em uma proposição mal formada, mas sua solução é possível pela análise das suas condições de verdade.

\section{Conclusão}

EM CONClusÃo, a SOLUÇÃo DE Odon SE MOSTRA como uma sexta via no leque de soluções expostas na primeira parte desta exposição. Não se trata de destituir o paradoxo de todo sentido tal como a via cassante pretendia, tampouco de banir a auto-referência do espectro proposicional, tal como predicava a via restringente. No entanto, a solução de Odon mantêm alguma familiaridade com a solução de Bradwardine e aquela que Buridan irá desenvolver, na medida em que a falsidade significada pelo predicado conduzirá à falsidade da proposição. No entanto, diferentemente de Bradwardine e Buridan, Odon não invoca o postulado segundo o qual "toda proposição, se implica o falso, não pode ser verdadeira". Odon se concentra sobre o que é significado pelo predicado em função da sua incompatibilidade com forma afirmativa da proposição. Segundo essa compreensão, se tomássemos a seguinte versão do paradoxo: "eu não estou dizendo a verdade", a incompatibilidade se daria entre a forma negativa da proposição e o predicado "verdade". Ao nosso ver, uma solução do paradoxo nos termos propostos por Odon não encontra par na literatura medieval sobre os paradoxos. 
Aristóteles. (1975). Refutações Sofisticas. Aristoteles Latinus, IV. 1-3, De sophisticis elenchis. B.G. Dod (Ed.). Leiden: E.J. Brill.

Biard, J. (1993). Jean Buridan, Sophismes. Collection Sic et Non. Paris: Vrin.

Buridan, J. (1977). Sophismata. T.K. Scott (Ed.). Stuttgart-Bad Cannstatt: Frommann-Holzboog.

Bradwardine, T. (1970). Insolubilia. M.L. Roure (Ed.), La problématique des propositions insolubles du XIIIe siècle et du début du XIVe [...]. Paris: AHDLMA, XXXVII.

Odon, G. (1997). De duobos communissimis principiis scientiarum. L.M. Rijk (Ed.), Opera philosophica, Vol. I: "Logica”, Livro III. Leiden: Brill.

Perini-Santos, E. (2011). John Buridan's Theory of Truth and the Paradox of the Liar. Vivarium, 49(1-3), pp. 184-213.

Read, S. (2002). The Liar Paradox from John Buridan back to Thomas Bradwardine. Vivarium, 40(2), pp. 189-218.

Read, S. (2009). Plural Signification and the Liar Paradox. Philosophical Studies: An International Journal for Philosophy in the Analytic Tradition, 145(3), pp. 363-375.

Rijk, L.M. de. (1966). Some Notes on the Mediaeval Tract De insolubilibus, with the Edition of a Tract Dating from the End of the Twelfth Century. $V i$ varium, 4 , pp. 83-115.

Scotus, J.D. (1639). Quaestiones super libros Elenchorum. Wadding (Ed.), Opera Omnia. Lyon: Laurentius Durand, (reimpresso Hildesheim 1968).

Spade, P.V. (1987). Five Early Theories in the Mediaeval Insolubilia-Literature. Vivarium, 25(1), pp. 24-46.

Spade, P.V. (1983). The Semantics of Terms. N. Kretzmann, et al. (Eds.), The Cambridge History of Later Medieval Philosophy (pp. 188-196). Cambridge: Cambridge University Press.

Spade, P.V. (1975). Subsidia Mediaevalia. The Mediaeval Liar: A Catalogue of the Insolubilia-Literature Vol. 5. Toronto: Pontifical Institute of Mediaeval Studies. Spade, P.V. (1981). Insolubilia and Bradwardine's Theory of Signification. Medioevo: Revista di storia della filosofia medievale, 7, pp. 115-134. 